\title{
Honduras: Posparto y post-aborto, momentos para hablar de planificación familiar
}

Frontiers in Reproductive Health

Follow this and additional works at: https://knowledgecommons.popcouncil.org/departments_sbsr-rh

Part of the Demography, Population, and Ecology Commons, Family, Life Course, and Society Commons, Maternal and Child Health Commons, and the Public Health Education and Promotion Commons How does access to this work benefit you? Let us know!

\section{Recommended Citation}

"Honduras: Posparto y post-aborto, momentos para hablar de planificación familiar," FRONTERAS Resumen de Investigación Operative. Ciudad de México: Population Council, 2001. 


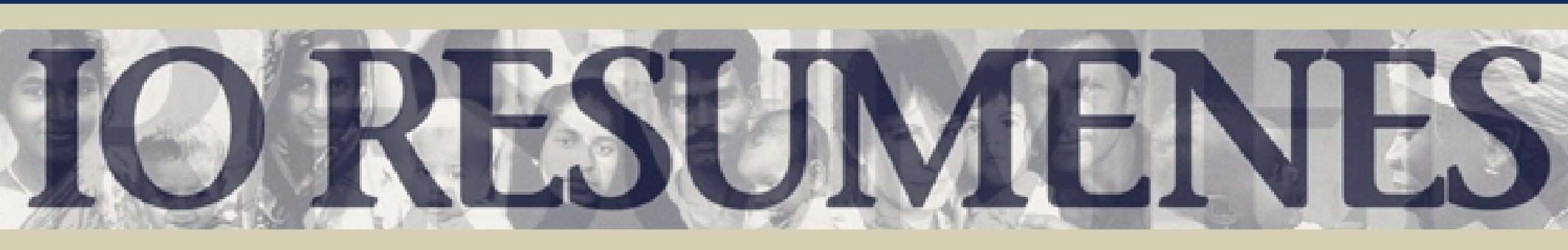

\section{Honduras Opciones Anticonceptivas \\ Posparto y postaborto, momentos para hablar de planificación familiar}

\author{
Investigación \\ operativa
}

Resumen 17

\begin{abstract}
Cuando los proveedores de cinco hospitales en Honduras recibieron capacitación para proporcionar consejería a las pacientes en el posparto y el postaborto, la proporción de mujeres que recibieron información sobre planificación familiar se duplicó, y la proporción que recibieron un método anticonceptivo, se triplicó. La intervención, resultado de la expansión de un proyecto anterior de investigación operativa, será implementada en cinco hospitales más.
\end{abstract}

\section{Antecedentes}

Aproximadamente la mitad de los partos en Honduras son atendidos en un hospital. Sin embargo, los hospitales generalmente no ofrecen servicios de planificación familiar a las pacientes en el posparto o el postaborto. En 1999, la Secretaría de Salud de Honduras (SSH) y el Population Council iniciaron un proyecto de dos años con el fin de ampliar el acceso a la consejería y a los servicios de planificación familiar (PF) después de un parto o de haber recibido tratamiento por un aborto incompleto. $\mathrm{La}$ intervención se realizó basándose en un proyecto previo del Population Council que mostró que el 30 por ciento de las mujeres hospitalizadas por parto o por complicaciones relacionadas con un aborto estaban interesadas en obtener un método de PF antes de ser dadas de alta.

En los cinco hospitales que participaron en el estudio, el parto es el motivo más frecuente de ingreso; cada uno de los hospitales atiende en promedio 4,800 partos al año. También es relativamente común el ingreso de pacientes por complicaciones de un aborto, con un promedio de 400 casos al año. La intervención estuvo compuesta de estos elementos: (1) capacitación de todo el personal que atiende a las pacientes de posparto o postaborto en la promoción y consejería de los servicios de PF; (2) capacitación a 65 médicos y enfermeras en metodología anticonceptiva;
(3) provisión de métodos, equipo y ayudas educativas de PF, como folletos, videos y rotafolios, y (4) supervisión y monitoreo de las actividades. Para documentar el progreso, se recolectaron las estadísticas de servicio trimestralmente en cada uno de los hospitales y se realizaron encuestas de línea de base (474 casos posparto y 24 postaborto) y de línea final (571 casos posparto y 71 postaborto). Además, el personal del hospital llevó a cabo encuestas trimestrales entre las pacientes (un promedio de 238 mujeres en el posparto y 26 en el postaborto).

\section{Hallazgos}

- El número de pacientes posparto que recibieron un método anticonceptivo se triplicó después de la intervención, y en el grupo de pacientes postaborto, se cuadruplicó (ver el cuadro en la siguiente página). De manera similar, el número de pacientes posparto que recibieron información sobre PF se duplicó, mientras que entre las pacientes postaborto, el número se cuadruplicó.

- Después de la intervención, un mayor número de mujeres solicitaron un método, y la mayoría efectivamente lo recibieron. La proporción de mujeres que solicitaron un método en el posparto o el postaborto y no lo recibieron, disminuyó considerablemente con la intervención. 
Porcentaje de mujeres que recibieron servicios de PF

\section{Servicios de PF Línea de base Línea final}

Recibieron un método de PF durante su estancia hospitalaria

Posparto

Postaborto

10

13

33

Deseaban un método pero no lo recibieron

Posparto

Postaborto

$\begin{array}{rr}41 & 7 \\ 48 & 21\end{array}$

- Hallazgos previos a la intervención revelaron una evidente necesidad de información y métodos de PF. Durante la encuesta de línea de base, el 65 por ciento de las mujeres en el posparto dijeron que su embarazo no había sido planeado, y el 38 por ciento dijeron que hubieran preferido esperar más tiempo antes de embarazarse (ver la figura abajo). Cerca de la mitad (46\%) no deseaban tener más hijos. Antes de la intervención, sólo tres de los hospitales ofrecían servicios de PF a las clientas en el posparto y el postaborto, y sólo dos de ellos contaban con los suministros necesarios para darlos.

La mezcla de métodos fue más variada durante la intervención. La elección en el posparto cambió del DIU y la esterilización voluntaria de manera casi exclusiva, a un mayor uso de métodos temporales, como los condones y el método de la amenorrea por lactancia. Las mujeres en el postaborto optaron por una mezcla de esterilización, inyectables o anticonceptivos orales, en vez de limitarse sólo a la esterilización voluntaria.

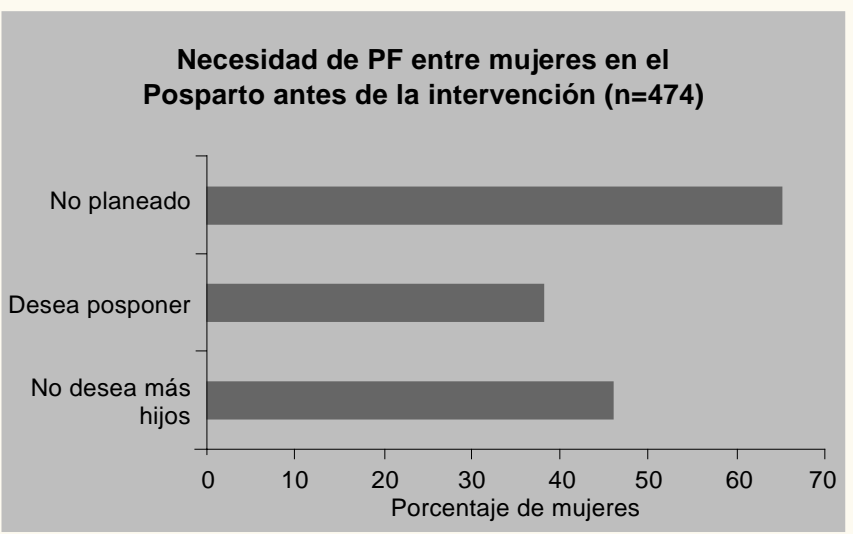

\section{Implicaciones normativas}

- El diseño del proyecto permitió reconocer el progreso al incluir la recolección y presentación de la información de manera periódica, y ofreció oportunidades para buscar soluciones a los problemas que fueron surgiendo durante la intervención. El firme compromiso de los directores de los hospitales también contribuyó al éxito del proyecto. Los programas para mejorar los servicios deben incorporar la recolección periódica de información y deben asegurar la participación y el apoyo tanto de los directores de los programas como de los proveedores.

Las auxiliares de enfermería atienden más de la mitad de los partos en algunos de los hospitales. Por lo tanto, deben recibir capacitación para proporcionar todos los métodos anticonceptivos temporales, incluyendo el DIU.

\section{Utilización}

Debido al éxito del modelo en estos cinco hospitales, la Agencia de los Estados Unidos para el Desarrollo Internacional proporcionó apoyo a EngenderHealth para continuar la expansión del mismo en cinco hospitales más en Honduras.

\section{Fuente:}

Medina, Ruth, Ricardo Vernon, Irma Mendoza y Claudia Aguilar. 2001. "Expansion of postpartum and postabortion contraception in Honduras [Expansión del uso de anticoncepción en el posparto y el postaborto en Honduras]," FRONTIERS Final Report. Washington, DC: Population Council. Disponible en nuestro portal: http://www.popcouncil.org/pdfs/frontiers/FR FinalReports/

Honduras contraception.pdf o por correo electrónico: frontiers@pcdc.org

Este proyecto se llevó a cabo con el apoyo de la AGENCIA DE LOS ESTADOS UNIDOS PARA EL DESARROLLO INTERNACIONAL (USAID) bajo el acuerdo de cooperación No. HRN-A-00-98-00012-00.

\section{Population Council}

